\title{
Bases fundiárias da governança ambiental: um estudo de caso sobre barragens
}

\section{Agrarian bases for environmental governance: a case study on dams}

Rodrigo Constante Martins - Professor do Departamento de Sociologia e do Programa de Pós-Graduação em Sociologia da Universidade Federal de São Carlos - UFSCAR: E-mail: rmartins@ufscar.br

\section{Resumo}

O objetivo deste trabalho é interpretar os contextos de relações de poder na gestão de águas em áreas de barragens de usinas hidrelétricas (UHE's). Interpreta os conflitos envolvidos na gestão dos recursos hídricos a partir do caso do município de Barra Bonita, localizado na região central do estado de São Paulo, às margens do rio Tietê. $\mathrm{O}$ estudo revela que o município tem sua história marcada pela construção do reservatório da Usina Hidrelétrica de Barra Bonita e de sua respectiva barragem, ocorrida na década de 1950. Evidencia ainda como a redefinição das relações fundiárias decorrente da construção da barragem e do reservatório hídrico vem condicionando, desde a década de 1990, a estruturação regional da gestão descentralizada e participativa das águas. Em suas conclusões, o artigo destaca que as conjunturas locais de exclusão social tendem a ser refletidas nas novas instâncias descentralizadas de gestão dos recursos territoriais - tais como os Comitês de Bacias Hidrográficas.

\section{Palavras-chave}

Sociedade e recursos hídricos. Barragens. Dinâmica agrária. Ruralidade

\begin{abstract}
This paper aims to understand the contexts of power relations in water management in areas of hydropower dams. It interprets the conflicts involved in water resources management from the case of Barra Bonita city, located near the margins of Tietê river, in the central region of São Paulo state. The study unveils that the city's history has been marked by the construction of the reservoir and the dam of Barra Bonita hydropower plant, which occurred in the 1950's decade. It also highlights how the redefinition of land relations resulting from the construction of the dam and the water reservoir has been conditioning the regional structure of decentralized and participatory water management since the 1990s. The article concludes that local conjunctures of social exclusion tend to be reflected in the new decentralized instances of land resources management - such as river basins committees.
\end{abstract}

\section{Keywords}

Society and water resources. Dams. Agrarian dynamics. Rurality 


\section{INTRODUÇÃO}

A criação de mecanismos alternativos de regulação das relações da sociedade com a natureza vem revelando novos temas para o debate sobre desenvolvimento territorial. Dentre tais temas, tem recebido especial destaque aqueles relativos à democracia decisória e à participação de distintos segmentos sociais na construção de metas socioterritoriais para os contextos de ruralidade. Ressaltando a importância da categoria território, vários trabalhos vêm debatendo o funcionamento das instituições descentralizadas de gestão dos recursos naturais.

No estado de São Paulo, uma das expressões desta descentralização institucional são os Comitês de Bacias Hidrográficas. Criados como colegiados regionais formados por diversos segmentos sociais, esta inovação institucional segue evidenciando, em que pese seu avanço na direção contrária ao centralismo decisório de outrora, certas fragilidades quanto aos seus sistemas de representação social e de construção de intervenções políticas. Em determinadas circunstâncias, tem sido possível constatar que a democracia formal presente na composição destas modalidades de instâncias de gestão pode não resistir às relações de poder fixadas nos territórios.

O objetivo deste trabalho é apresentar uma interpretação sociológica dos contextos de relações de poder na gestão de águas em áreas de barragens de usinas hidrelétricas (UHE's). Pretende, mais especificamente, interpretar os conflitos de interesses envolvidos na gestão dos recursos hídricos a partir do caso do município de Barra Bonita, localizado na região central do estado de São Paulo. Como se argumentará adiante, tem sua história marcada pela construção do reservatório da Usina Hidrelétrica de Barra Bonita e de sua respectiva barragem, ocorrida na década de 1950.

Além desta apresentação, o texto divide-se ainda em outras quatro sessões. A seguir são apresentados os procedimentos metodológicos de pesquisa qualitativa adotados na realização do estudo de caso. $\mathrm{Na}$ terceira sessão são demarcados os processos sociais envolvidos na dinâmica fundiária do município após a construção da UHE. Na quarta sessão discuti-se o impacto desta dinâmica fundiária no aparato regional de gestão das águas - a saber, o Comitê de Bacia Hidrográfica Tietê-Jacaré - e, em seguida, são apresentadas as considerações finais do estudo.

\section{PROCEDIMENTOS DO ESTUDO DE CASO}

O espaço foco do estudo apresentado neste artigo é o município de Barra Bonita, localizado na região central do estado de São Paulo. Fundado em 1912, o município, até 1930, tinha a cafeicultura como principal atividade produtiva. Em meados do último século a cultura canavieira passou a ganhar espaço crescente na economia regional, tendo sido impulsionada, principalmente, pela fixação, em 1948, de uma grande usina de açúcar e álcool no município.

Com população estimada em 37.276 habitantes, Barra Bonita faz parte da área de influência direta do reservatório da Usina Hidrelétrica de Barra Bonita, hoje sob concessão da empresa norte-americana AES (Applied Energy Services), e pertence, na estrutura estadual de gestão de águas, à Unidade de Gerenciamento de Recursos Hídricos (UGRH) Tietê-Jacaré. As cadeias agroindustriais sucocítricas e sucroalcooleiras são responsáveis por grande parte da dinâmica econômica da região. Do ponto de vista ambiental, a área rural da unidade de gerenciamento possui alta suscetibilidade a processos erosivos e elevada demanda de água para fins de irrigação (cerca de $58 \%$ da demanda total da unidade), o que já a coloca em situação crítica de disponibilidade hídrica (SÃO PAULO, 2000).

Para compreender a história fundiária regional desde a construção da UHE de Barra Bonita, optou-se pela adoção de procedimentos de caráter qualitativo para a pesquisa de campo. Utilizou-se informações obtidas por meio de coleta de relatos orais, entrevistas semi-estruturadas e observações de campo. Os informantes foram selecionados a partir dos critérios de amostragem de propósito (purposeful sampling) de Patton (2002).

A fase de campo deste estudo foi realizada no período de março de 2000 a fevereiro de 2004. O contato com os informantes selecionados foi realizado através dos procedimentos de sistemas de rede, tais como propostos inicialmente por Furtado (1993) e adaptados por Martins (2004) para estudos em comunidades predominantemente agrícolas. Este sistema exigiu a identificação, através de idas prévias a campo, de um agente social com relações de grande amplitude horizontal, capaz de enquadrar-se como elemento-polo da rede de informantes. No caso de Barra Bonita, a posição de elemento-polo foi ocupada pela Associação de Fornecedores de Cana-de-açúcar, que juntamente com outros 15 produtores de cana-de-açúcar e com a Unidade Agroindustrial do município, formaram o quadro final da rede de informantes. 
A tipologia dos informantes seguiu o seguinte perfil: a) a Unidade Agroindustrial (usina); b) os médios fornecedores de cana-de-açúcar do município, com áreas superiores a 80 hectares; c) os pequenos fornecedores de cana-deaçúcar, com áreas inferiores a 79 hectares; e d) os arrendadores de terras que também compõem o mercado local de força de trabalho temporária. Em alguns casos, o entrevistado fez parte de duas ou mais categorias, o que demonstra, per si, a complexidade da teia de relações fixada no território em questão.

A instituição analisada como palco da reprodução dos interesses sociais dos agricultores do espaço em foco foi o Comitê de Bacia Hidrográfica Tietê Jacaré (CBH-TJ). Amparado pelo debate institucional sobre o princípio da subsidiaridade $^{1}$, o Comitê de Bacia é, no estado de São Paulo, componente do Sistema Integrado de Gerenciamento de Recursos Hídricos (SIGRH), criado pela Lei Estadual 7.663, de 1989. Também chamado de "parlamento das águas", o Comitê é um colegiado regional composto por diversos segmentos sociais envolvidos na gestão dos recursos hídricos. Atua na definição das prioridades, programas e projetos componentes do Plano Estadual de Recursos Hídricos. Atualmente, na estrutura do SIGRH, o estado é divido em 20 Comitês de Bacias Hidrográficas.

\section{A HISTÓRIA DO ESPAÇO SOCIAL}

A dinâmica socioeconômica do município de Barra Bonita atrelouse, ao longo dos últimos 40 anos, ao ritmo de crescimento da agroindústria sucroalcooleira do estado de São Paulo. A presença de uma grande unidade agroindustrial do setor no município foi fator decisivo nos rumos tomados pela expansão da agricultura regional na segunda metade do século XX. Em 2003, a cultura canavieira era responsável por 93\% das áreas de exploração agrícola do município - o que correspondia a cerca de 10 mil hectares de terras (CASA DA AGRICULTURA ANTONIO ORTIGOSSA, 2001).

Atualmente, a referida unidade agroindustrial é a principal catalizador regional de força de trabalho, possuindo um quadro de aproximadamente 6.000

De acordo com tal princípio, toda a ação que pode ser decidida e implementada no âmbito da localidade, não deve ser submetida à decisão de nível hierárquico superior, decorrendo daí uma divisão funcional em termos de arranjos institucionais e de envolvimento dos interesses sociais locais na construção de políticas no - e não para 0 - território. Para pormenores sobre 0 princípio da subsidiaridade, ver Scheneider e Volkert (1999). funcionários, dos quais $60 \%$ formam o que os gerentes da usina chamam de "mão de obra rural", ou seja, são trabalhadores envolvidos diretamente com o plantio e a colheita da cana-de-açúcar. Soma-se a estes ainda cerca de 2.000 trabalhadores contratados temporariamente no período de safra e antigos trabalhadores que, após serem demitidos pela usina ao longo da primeira metade da década de 90, formaram cooperativas de prestação de serviços para a própria empresa, desempenhando, no mais das vezes, a mesma atividade exercida nos tempos de funcionários efetivos.

Entre os anos de 2000 e 2003, a usina utilizou anualmente uma área de cerca de 77 mil hectares de produção agrícola, dos quais 18 mil eram de propriedade da empresa e 59 mil provinham de terras arrendadas. Nesta área, que abrangia territórios de seis municípios - Barra Bonita e outros cinco circunvizinhos -, a usina produziu, anualmente, cerca de 6 milhões de toneladas de cana-de-açúcar. A estes, somavam-se, ainda, cerca de 1 milhão de toneladas adquiridas junto a fornecedores, localizados em um raio de $75 \mathrm{~km}$ da usina ${ }^{2}$.

Todos os fornecedores de Barra Bonita pertencem a uma Associação Regional de Fornecedores, com sede no próprio município. Em entrevistas com a direção da associação e com alguns de seus fornecedores, pôde-se observar que a entidade se destaca menos por sua atuação política de defesa dos interesses dos associados junto à usina do que por seu quadro de prestação de serviços, dos quais se destacam a assistência médica e hospitalar e os descontos em vários ramos do comércio local.

Dos atuais 1.012 fornecedores associados, 145 são do município de Barra Bonita. Não obstante a proximidade geográfica com a sede da usina - condição que poderia também corresponder a laços mais estreitos de parceria -, a relação destes fornecedores com a empresa tem sido permeada por níveis distintos de tensão. Em grande medida, tal tensão associa-se ao pequeno volume de cana que a maior parte destes fornecedores dispõem anualmente para comercializar com a empresa, fato que, de antemão, nos dá um indicativo da importância da variável estrutura fundiária na compreensão do movimento de produção de valor neste espaço.

Segundo a gerência da empresa, este volume de cana ocupava à época pouco mais de $80 \%$ da capacidade industrial de moagem instalada na usina. O patamar máximo de processamento industrial, que girava em torno de 8 milhões de toneladas, foi atingido em meados dos anos 80, e conferiu à usina o título de maior unidade produtora de açúcar e álcool do mundo (CASA DA AGRICULTURA ANTONIO ORTIGOSSA, 2001). 
Do total de fornecedores do município de Barra Bonita, 8 possuem mais de 80 hectares de lavoura de cana-de-açúcar, sendo que destes apenas 1 possui área superior a 200 hectares. Neste seleto grupo de fornecedores, todos produzem cana na região há pelo menos 20 anos, sendo que os produtores mais novos, conforme definição dos próprios, são "herdeiros da atividade do pai". Outros 6 produtores que possuem área agrícola entre 50 e 80 hectares estão atualmente arrendando suas propriedades para a usina. Já o número de fornecedores cadastrados com área agrícola inferior a 80 hectares no município caiu, de acordo com os dados da Associação regional, de 216 para 131 fornecedores desde 1995 - uma retração de $37 \%$ em praticamente uma década. Deste montante, a grande maioria arrendou terras para a usina ${ }^{3}$.

Dentre as razões alegadas pelos pequenos agricultores para optarem pelo arrendamento de área agrícola, destacam-se as dificuldades de investimento na produção, e, particularmente, aquelas relativas aos investimentos para a adoção de técnicas de irrigação. Isto porque, diante da recorrência de longos períodos de estiagem na região, a irrigação tem se tornado fator essencial para a garantia da colheita agrícola. No caso da usina, titular das lavouras próximas aos principais cursos d'água do município (incluindo as margens do reservatório da UHE de Barra Bonita), o emprego das técnicas de irrigação é um incremento de capital; no caso destas pequenas unidades de produção agrícola, organizadas em sua maioria a partir da base familiar, a ausência da tecnologia é uma restrição adicional à sua reprodução social.

$\mathrm{Na}$ avaliação dos gerentes da unidade agroindustrial do município, neste movimento de centralização de capital, os pequenos fornecedores que assumiram a função de arrendadores de terras para a empresa tornaram-se isentos de gastos e demais responsabilidades sobre o perfil técnico da produção, além de ainda terem garantida renda pelo interesse da empresa em cultivar suas terras. Não obstante tal avaliação, essa política de arrendamento da empresa surge para os menores fornecedores não como opção, ou seja, como alternativa diante de um leque de possibilidades, mas sim como condição única de manterem-se atrelados ao movimento de produção de valor naquele território. Caso contrário, provavelmente, tornar-se-iam novos membros do processo de mobilidade

3 O contrato de arrendamento estabelecido entre a usina e os proprietários de áreas agricultáveis segue a forma de arrendamento em dinheiro, onde a empresa para um preço fixo por hectare utilizado, independente das condições de fertilidade do solo ou da proximidade da área agrícola em relação aos cursos d'água da região. espacial característico da modernização da produção canavieira do estado de São Paulo.

Em alguns casos, estes pequenos arrendadores assumem nova condição subalterna de participação na produção local de valor excedente, qual seja, a de força de trabalho temporária da própria empresa arrendatária.

Entre produzir e dever pra banco, ou arrendar terra para a usina, eu prefiro arrendar. Não porque eu ganho dinheiro assim, porque o que eles pagam também não dá pra viver. Mas pelo menos eu tenho tempo livre pra fazer bicos na cidade e colher cana por aí. Esse último ano aí eu colhe cana quase que só pra usina mesmo! (Arrendador/trabalhador temporário, 30 anos)

O grau de dependência dos pequenos fornecedores para com a usina é reforçado pela dificuldade de comercialização da colheita com compradores de fora da região. Os custos de transporte que estes agricultores teriam que arcar são apontados como um dos empecilhos à busca de novos mercados. Além disso, o funcionamento do mercado local de comercialização das safras corresponde a um monopsônio (ainda que as condições formais de livre comércio permaneçam presentes na região), situação que os fornecedores preferem preservar, mesmo que isso signifique a reiteração de relações de domínio social.

Infelizmente, nós não temos mais onde recorrer. Não tem mais o instituto ${ }^{4}$. Não tem mais órgão do governo que olhe pra isso aqui. Todo dia vem comprador de cana aqui.

Eles pagam bem a tonelada [enfático]. Chegam no canavial e calculam, dá o dinheiro e corta a cana. Hoje mesmo veio um rapaz querendo comprar aqui 2 mil toneladas nossa. Mas nós não vamos vender. Como nós vamos vender? A gente vive da cana, sempre vendeu pra usina. Mesmo com as dificuldades, as dívidas - e a gente tá devendo bastante - a gente tem contrato com a usina. Nosso contrato é de seis anos. E se no ano que vem acontece a crise desses anos atrás, e se a usina fala "eu não quero a sua cana, você já vendeu pra outro, agora vai vender lá”. Eles podem falar assim, não pode? E como nós vamos fazer? (agricultor-fornecedor, 73 anos)

O instituto a que se refere o agricultor é o IAA (Instituto do Acúcar e do Álcool), instinto no início da década de 90 pelo governo Collor. Até então, o IAA havia se caracterizado como um importante intermediador nas disputas entre plantadores de cana e usinas. Atuava na negociação de problemas relacionados ao preço da cana, no levantamento dos estoques das usinas para reajuste do preço da cana e no levantamento de dados técnicos e produção genética, dentre outros. 
Diferentemente do que ocorre com os maiores fornecedores da usina que compram insumos diretamente com a rede de fabricantes -, é no ato da comercialização da safra que os pequenos fornecedores adquirem os insumos necessários para a próxima colheita. Esta aquisição também é feita diretamente com a usina, que fornece, na maioria das vezes, agroquímicos (sobretudo herbicidas) como parte do pagamento da safra do agricultor. Tal troca assume particular importância na medida em que orienta decisivamente a conduta do fornecedor no momento da realização de sua mercadoria: nesta relação, são reafirmadas não só sua condição de subsunção frente à cadeia agroindustrial, mas também o perfil técnico a ser seguido por este agricultor.

\section{DA QUESTÃO FUNDIÁRIA À QUESTÃO AMBIENTAL}

A despeito da região de Barra Bonita enfrentar atualmente uma situação crítica de disponibilidade hídrica, os responsáveis pela produção agrícola da usina têm enfatizado a crescente necessidade de se expandir o conhecimento e as técnicas de plantio da cana irrigada na região. Isto porque, nos últimos três anos, a diminuição das chuvas tem afetado o desempenho das lavouras, elevando o tempo de maturação da cana em alguns casos e, em outros, causando mesmo queda de produtividade. Neste período, a usina e seu maior fornecedor (com cerca de 480 hectares de lavouras de cana) realizaram a chamada "irrigação de choque", qual seja, aquela desenvolvida em locais pontuais da lavoura, onde a necessidade imediata de água é premente. Evidentemente, esta modalidade de irrigação não pôde ser praticada pelos pequenos fornecedores do município, visto que sua realização implicaria no uso de tecnologias restritas àqueles produtores com elevado nível de capitalização. No caso da usina, as normas legais de requisição de outorga para a captação de água foram ignoradas. No caso do fornecedor, além de desconhecer tais normas, a reação em saber, através do entrevistador, da existência de tal aparato legal, foi motivo de indignação.

Nós conhecemos os procedimentos e somos favoráveis. Cumprimos os procedimentos aqui na usina, em nossa divisão industrial. Agora na lavoura, no meio do canavial, se o regulamento quiser ser cumprido ele terá que entrar lá. Tem que cruzar o canavial na hora que for![enfático]. Quem trabalha com agricultura sabe que é assim que a coisa funciona. Eu não posso pedir pra planta esperar o fiscal chegar. É preciso haver bom senso aí (Unidade Agroindustrial)
Por que eu tenho que pedir licença pra alguém pra tirar água do rio? O rio não tem dono! E se tiver dono, o dono que apareça e venha falar comigo [fala austera]. É como aqui na minha casa: se alguém entra para levar algo que é meu, eu vou atrás e garanto o meu direito de dono. Agora, onde está o dono da água? Só faltava alguém querer ser o dono da água! Nem eu, nem você, nem governo; ninguém pode ser dono disso! A água está aí para gente sobreviver, produzir alimento. [...] Eu não estou sujando a água, nem nada. E mesmo que estivesse, o governo que mande a Cetesb vir aqui me multar. Não é ela que faz isso? Então, eles que venham atrás, não sou eu quem tem que ir atrás deles (Fornecedor, 71 anos).

No depoimento da gerência da usina, é sintomático o modo como a empresa espera que a regulamentação do acesso à água se adeque ao ritmo temporal de sua estrutura de produção de valor. O canavial é representado como um universo obscuro que deve ser enfrentado em toda sua robusteza pela fiscalização ambiental. A previsibilidade característica da modernização das práticas agrícolas capitalizadas é neste momento deixada de lado em prol da urgência da planta. Tal urgência, que em outras circunstâncias poderia ser racionalmente calculada por meio de técnicas agronômicas, é alçada à condição de argumento supostamente irrefutável para o não cumprimento dos dispositivos legais. Sem embargo, esta situação inimaginável na agricultura moderna, com o administrador agrícola descobrindo quase por eventualidade as necessidades imediatas de água da planta, pode expressar menos uma limitação técnica efetiva do processo modernizador da agricultura regional do que um apelo discursivo rumo à justificação do acesso não legítimo da empresa ao recurso.

O relato do fornecedor, por sua vez, revela que, embora ciente dos mecanismos tradicionais de fiscalização da qualidade dos corpos d'água - vide referência à Cetesb (Companhia de Tecnologia de Saneamento Ambiental, órgão fiscalizador da Secretaria do Meio Ambiente do governo de São Paulo) - este desconhece as inovações institucionais operadas no sistema estadual de gestão de águas ao longo da última década. Outrossim, irrompem na fala do fornecedor pressupostos de liberdade absoluta de uso do recurso, ainda que, do ponto de vista institucional, haja restrições ao livre acesso à água desde o Código das Águas de $1934^{5}$. No entanto, a história de acesso não arbitrado deste agricultor

5 O Código das Águas, estabelecido pelo Decreto Federal no 24.643 de $10 / 07 / 1934$, assegurava
o uso gratuito de qualquer corrente ou nascente de água para as necessidades básicas de
sobrevivência humana, permitindo a todos o uso do recurso conforme regulamentos
administrativos. Impedia, no entanto, a derivação das águas públicas para aplicação na
agricultura e indústria sem a existência de concessão. De um modo geral, embora tenha se 
junto ao recurso sobrepõe-se, no âmbito de sua experiência social, aos aparatos legais de regulação. Ou seja, sua compreensão sobre seu acesso ao recurso extrapola os arranjos formais direcionados ao estabelecimento de normas de uso. Remontando à questão da propriedade, este agricultor nada mais faz do que exigir a aparição de um agente que, assim como ele, defenda a parcela do território que lhe pertençe. Contudo, embora tenha claro seu direito de propriedade de terras, o agricultor insinua uma defesa quase russeauniana do livre acesso ao recurso natural que torna possível a utilização produtiva da terra, e conclui: "ninguém pode ser dono disso"

Já entre os pequenos agricultores do município, há um nítido desconhecimento sobre o sistema estadual de gestão de águas. A quase totalidade dos agricultores entrevistados não possui esclarecimento sobre a participação dos usuários de recursos hídricos no sistema. Alguns agricultores chegam mesmo a ignorar a existência dos Comitês de Bacias Hidrográficas, e para os que já ouviram falar neste termo, é comum identificá-lo como órgão governamental frio e distante, ou seja, fazendo uso da terminologia weberiana, como instância de poder burocrático-administrativa, que atua presumidamente com indiferença ante as circunstancialidades dos interesses do cotidiano local.

Quando esclarecidos sobre as funções do comitê e a possibilidade de participação efetiva do segmento agrícola na instância de gestão, os até então desconhecedores da estrutura já vislumbram a nova instituição a partir das relações de dominação da agricultura local:

Nessa parte que envolve a política aí é a usina quem deve entrar. Eles irrigam cana, precisam de água pra muita coisa lá dentro. Água mesmo nós não usamos aqui. A gente não tem as máquinas pra isso. Agora a usina sim. Aqui ninguém vai discutir isso com eles. Acho que é até por isso que a gente não conhece esse comitê. Mas a usina deve conhecer e esse comitê também tem que conhecer a usina, pois é só ela que tira água do lado de cima do Tietê (Agricultorfornecedor, 48 anos).

constituído no primeiro passo rumo a um modelo burocrático de gerenciamento das águas no Brasil, o Código de Águas limitava-se às ênfases nos temas relativos ao abastecimento da região semiárida brasileira e ao aproveitamento hidroenergético das demais regiões do país.

6 A passagem que segue é elucidativa sobre os traços russeaunianos do depoimento do agricultor. Refletindo sobre o surgimento das relações de propriedade da terra, o filósofo francês conjectura que "o verdadeiro fundador da sociedade civil foi o primeiro que, tendo cercado um terreno, lembrou-se de dizer isto é meu e encontrou pessoas suficientemente simples para acredita-lo. Quantos crimes, guerras, assassinatos, misérias e borrores não pouparia ao gênero bumano aquele que, arrancando as estacas ou enchendo o fosso, tivesse gritado a seus semelhantes: Defendei-vos de ouvir esse impostor; estareis perdidos que os frutos são de todos e que a terra não pertence a ninguém." (ROUSSEAU, 1991, p. 259)
O "lado de cima do Tietê" a que se refere o agricultor é justamente a região do reservatório da UHE de Barra Bonita. As áreas marginais ao reservatório são ocupadas quase exclusivamente pela usina, seja com propriedades próprias ou arrendadas. Do ponto de vista da produção de valor, a localização das lavouras da usina em relação ao reservatório segue historicamente conferindo à empresa um diferencial de acumulação. Isto por conta das condições de fertilidade dos solos das margens do reservatório e do próprio clima da região. Conforme a gerência da empresa.

O montante deste volume [de produção] está ligado a uma região que produz cana em uma época em que normalmente a cana não está pronta ainda em outras regiões [...] Este vale do Tietê, onde existe a bacia de acumulação da represa, tem um tipo de solo com uma fertilidade muito boa, e nos permite esta vantagem (Unidade Agroindustrial).

Deste modo, enquanto a colheita da produção de cana-de-açúcar no estado de São Paulo inicia-se, normalmente, no final do mês de maio e se encerra no final do mês de outubro, a usina inicia a sua colheita no início de abril, encerrando-a no final de dezembro. Em virtude desta singularidade, a empresa construiu, ao longo de seu processo de acumulação, uma estrutura industrial que lhe permite absorver o total da cana colhida ao longo deste tempo estendido, o que também repercutiu em um modo mais intenso de exploração da força de trabalho (temporária e permanente) em sua produção.

Para aqueles agricultores que conhecem um pouco da estrutura estadual de gestão de águas, há um nítido desestímulo em tomar seu espaço como representante no segmento sociedade civil neste sistema. A título de ilustração, vale citar o caso de um dos membros da direção da Associação de Fornecedores, que nos relatou ter sido recentemente convidado para participar das reuniões do CBH-TJ, mas julgou não ser prioridade para a associação dedicar-se, até o momento, ao fortalecimento do seu espaço no sistema estadual de gestão de águas. Mesmo a usina, usuária de água para fins agrícola e industrial, prefere não participar diretamente da estrutura de gestão. De acordo com um de seus gerentes, neste momento, a usina julga mais vantajoso observar "de fora" os rumos que esta nova estrutura de gestão irá tomar. Ademais, conforme o depoimento a seguir, a unidade agroindustrial confia seus interesses setoriais a uma organização corporativa com forte influência no cenário da atividade agroindustrial do estado: 
Nós não estamos nos envolvendo diretamente no comitê, mas temos quem nos represente. A Unica tem assento por lá e defende os interesses de todo o nosso setor. Com eles dentro do comitê, não temos por que deslocar alguém para lá. [...]. Estamos absolutamente representados. Nós e toda a região, pois existe uma convergência de interesses para se gerar renda pra essa gente (Unidade Agroindustrial).

Nestas circunstâncias, a usina pode amparar-se, no que se refere aos seus interesses de acesso aos recursos hídricos regionais, na representação corporativa desempenhada pela União da Agroindústria Canavieira de São Paulo (Unica) junto ao CBJ-TJ ${ }^{7}$. Contudo, é notório que esta entidade corporativa de representação setorial partilha interesses com a unidade agroindustrial e não com o conjunto dos atores sociais envolvidos na produção sucroalcooleira. Os pequenos agricultores fornecedores da usina, por exemplo, não se encontram no espectro dos interesses da Unica. O fato de quase a totalidade dos fornecedores com áreas de lavouras inferiores a 79 hectares ter dificuldades de acesso à água para uso produtivo, por exemplo, não é um tema abordado pelos representantes do setor sucroalcooleiro no comitê. Sob tais circunstâncias, o comitê torna-se um instrumento de construção de vantagens econômicas para grupos sociais historicamente articulados e tradicionalmente hegemônicos em territórios específicos.

Além da falta de conhecimento sobre a estrutura do comitê e sobre as possibilidades de participação do segmento agrícola na gestão das águas regionais, também é notório, entre os pequenos fornecedores da usina, o desconhecimento sobre os principais instrumentos de gestão de águas utilizados pelo comitê. Dentre estes instrumentos, a cobrança pelo uso da água, que está em vias de aprovação pela Assembleia Legislativa do Estado de São Paulo e deverá imputarlhes ainda maiores restrições de acesso ao recurso, é absolutamente desconhecida pelos agricultores ${ }^{8}$.

A rigor, o projeto de cobrança pelo uso da água apóia-se no pressuposto da valoração ambiental - amparado conceitualmente nas teorias da microeconomia neoclássica - de que, ao ser levado a realizar cálculos de custo/benefício por meio de estratégias de precificação, o usuário estaria automaticamente sendo induzido a adotar comportamentos racionais de uso do recurso. No caso paulista,

7 A outra entidade que possui vinculo com a agricultura e que tem representação no CBH-TJ é a Associação Brasileira de Exportadores de Cítricos.

8 Sobre o contexto político da implementação da cobrança pelo uso da água junto ao setor agrícola do estado de São Paulo, ver Martins e Valencio (2003) os critérios de cobrança deverão ser elaborados pelos próprios Comitês de Bacias Hidrográficas, com participação direta da sociedade civil.

A despeito da gestão descentralizada da cobrança, dentre os pequenos agricultores de Barra Bonita, tal instrumento de gestão é diretamente associado ao governo estadual, cabendo apenas ao usuário pagar pela água que lhe for necessária. A participação do usuário - garantida tanto no projeto de lei estadual que dispõe quanto na própria estrutura deliberativa dos comitês de bacia hidrográfica - na definição dos critérios de cobrança e na determinação dos destinos da arrecadação dentro de sua bacia hidrográfica é compreendida por estes agricultores menos como realidade efetiva dentro do sistema de gestão de águas do que como retórica governamental para a legitimação de um novo modo de arrecadação monetária para os cofres públicos.

Sobre o princípio que fundamenta a cobrança - qual seja, o da valoração ambiental - a avaliação dos pequenos agricultores-fornecedores seguiu menos uma ótica coorporativa de defesa dos interesses da categoria do que numa interpretação particular dos limites de controle da sociedade em geral sobre os recursos hídricos.

O governo não pode produzir água, como ele vai cobrar por ela? A água é de todo mundo, dos bichos, das plantas, do homem, de todo mundo que precisa. O governo não pode cobrar por ela [elevando o tom da voz]. O governo não pode produzir água pra querer vender. Se secar o país, o governo morre junto! O governo tem que cuidar é do esgoto que vem pra água, o esgoto da cidade (Fornecedor/trabalhador temporário, 68 anos).

É difícil essa coisa de cobrar pela água, principalmente agora que tá faltando. Não tem água pra todo mundo. Agora é que o governo deveria dar um jeito de todo mundo ter água, e não deixar ninguém querer cobrar por ela. Isso poderia até ser considerado crime. Do jeito que tem aproveitador por aí, se não tomarem conta disso, logo vai ter gente querendo se aproveitar de quem não tem. [...] Você vê, é caro um pacote de farinha? Não é, mais tem muita gente que não tem dinheiro pra comprar. Essa é a realidade. Por mais que seja pouco o que se cobre pela água, vai ter gente que também não vai conseguir pagar. E quem não conseguir pagar, como fica? (Agricultor/fornecedor, 68 anos).

É marcante no depoimento destes agricultores o conjunto de representações culturais, próprio deste segmento social, que é preterido pelo princípio conceitual da valoração dos recursos naturais. Ao definir um valor monetário como 
indicativo da importância relativa de um recurso natural, consequentemente está se considerando que princípios de mercado são eficazes no direcionamento do comportamento dos grupos sociais usuários. No caso da valoração da água, é suposto que estes princípios de mercado estejam suficientemente incorporados pela sociedade de modo a suplantar mesmo os laços culturais que, no caso de alguns grupos sociais, possam se contrapor à lógica de significação dos processos políticos e econômicos próprios dos ambientes de mercado.

Tal movimento revela a tentativa de universalização do sujeito racional, do homo oeconomicus que toma forma nas demonstrações neoclássicas, no planejamento da gestão estadual de águas. Não obstante, ao nortear a gestão de políticas públicas, esta lógica universalizante se dissolve em meio à diversidade de interesses e de signos sociais e às distintas temporalidades responsáveis pelas concepções variadas de relação sociedade-natureza. No caso dos agricultores supra, a resistência aos mecanismos de valoração da água não se refere ao preço a ser cobrado pelo acesso ao recurso ou por seu descarte. As questões levantadas pelos agricultores são de ordens absolutamente diversas, relacionadas com dimensões simbólicas que remetem tanto à concepção do trabalho social como fundamento do valor econômico, quanto às circunstâncias de equidade social no acesso ao recurso.

Assim, a experiência cotidiana que os usuários do recurso construíram historicamente na região é o que influencia sobremaneira a compreensão social da lógica de valoração ambiental. É justamente sobre nesta experiência que se fundamentam as assertivas dos agricultores de que somente pode ser vendido o que é produzido, trabalhado, transformado através do trabalho social; ou de que $o$ acesso à água, assim como o acesso a um pacote de farinha, é um indicador simultaneamente material e simbólico das desigualdades sociais produzidas no território. Neste caso, não se trata de um conhecimento teórico que se esforça em enquadrar a realidade contraditória da produção de valor em seus conceitos - como poderia bem sugerir uma reflexão marxista-estrutural -, mas sim do modo de experimentação social do território e de seus recursos por via dos processos de trabalho e das práticas de comercialização também experimentadas pelos pequenos agricultores. Ou, como nos diria Thompson (1981, p. 182), tratam-se de práticas de

pessoas que experimentam suas situações e relações produtivas determinadas como necessidades e interesses como antagonismos, e em seguida "tratam" essa experiência em sua consciência e sua cultura das mais complexas maneiras e em seguida agem, por sua vez, sobre sua situação determinada.
Sem embargo, a conduta econômico-racional universalizante que o princípio da valoração aspira obter particularmente dos agricultores parece constituir-se em uma frágil abstração, posto que se refere apenas a um dos aspectos da complexa teia de relações que conduzem grupos sociais a determinados comportamentos frente ao meio biofísico. Construções simbólicas, como as apresentadas nos depoimentos supra, são compostas de códigos de conhecimento particulares e concepções de destino também bastante definidas.

São justamente estas construções que compõem a complexidade do território. Reiterando o argumento de Leff (2003), compreender o território significa interpretar as formas distintas de construção dos modos de vida, de identidades culturais e de experiência social sobre as potencialidades ecológicas. Trata-se do espaço onde se manifestam diferentes temporalidades, diferentes formas de conciliação entre o tradicional e o moderno, entre modos 15 distintos de apropriação e uso dos recursos naturais. No caso das áreas rurais, estas relações tornam-se ainda mais complexas, posto que a proximidade das sociedades rurais com as variadas funções ecossistêmicas permite a construção social de realidades diversas, com conjuntos de relações culturais, econômicas e políticas de ordenamento do território também bastante amplos.

Do ponto de vista analítico, conforme também sugere Godelier, é fundamental que a apreensão dos elos significativos para a compreensão da interação sociedade-natureza não se restrinja à conduta econômica; ou seja

[...] é necessário analisar cuidadosamente o sistema das representações que os indivíduos e os grupos, membros de uma determinada sociedade, formulam sobre o seu meio, pois é a partir destas representações que os indivíduos ou os grupos atuam sobre o meio. (GODELIER, 1981, p. 53)

Tanto os sistemas de representações sociais interferem no tipo de conduta dos grupos sociais diante dos recursos ecossistêmicos que a unidade agroindustrial do município de Barra Bonita, visando assegurar seu acesso à água em longo prazo, defende a precificação do recurso:

Nosso uso da água é muito particular. É difícil dizer como e quando precisaremos. [...] Nós pegamos águas de açudes ou mesmo rios, que, quando você precisa, dá uma represada na hora, puxa a água, e irrigou ali tchau, desmonta e vai embora. [...] Por exemplo, eu vou utilizar a água de um determinado local, preciso utilizar a água naquele momento porque na agricultura é assim, eu não posso pedir para a planta esperar. Aí eu vou lá com o meu equipamento e como eu devo proceder? 
Quem vai medir depois? E a agilidade disso? Acho que se eu for pagar eu tenho direito de exigir no mínimo a agilidade do serviço, não é? [...] Somos favoráveis a essa cobrança neste sentido: entendemos a necessidade de racionalizar o uso da água e estamos dispostos a colaborar, mas também queremos garantias [...] na qualidade deste serviço e a garantida de que teremos água (Unidade Agroindustrial).

A rigor, o modo como a Unidade Agroindustrial compreende o tema da valoração da água é, do ponto de vista cultural, a expressão do modo como a própria empresa experimenta suas relações cotidianas com seus trabalhadores, fornecedores e demais membros envolvidos na produção agroindustrial de valores excedentes. A relação monetária é tomada pela empresa como garantia, em longo prazo, de acesso ao recurso. Neste caso, trata-se menos do entendimento sobre a racionalização do uso do que de uma posição de hedgers por parte da usina?.

De outra parte, em termos de lógica discursiva, os valores não econômicos expostos nos depoimentos dos pequenos agricultores representam, diante das disposições estruturadas das práticas da empresa, ilhas de primitivismo ante a emergência do moderno na arena rural. Este modo de interação social, tributário da razão utilitarista própria das relações capitalistas modernas, é composto por interesses materiais e dimensões simbólicas que divergem em muito das representações que escapam do universo dos fluxos de oferta e demanda dos mercados econômicos. Neste sentido, os princípios da valoração ambiental relacionam-se estritamente com o universo e as representações sociais da empresa capitalista, ainda que ao tornar-se prática de política ambiental seja universalizado para toda a sociedade. Ao prontificar-se a tal universalização, a política alicerçada nos princípios da valoração não só nega a diversidade do olhar social sobre a natureza, mas também serve às relações de dominação social fixadas nos territórios.

Isto significa que mesmo as intervenções de política ambiental que deverão ser gerenciadas no território, como é o caso da cobrança pelo uso da água, reproduzem as desigualdades sociais da localidade. A possibilidade formal de participação dos diversos grupos sociais na gestão dos recursos hídricos encontra seus limites na própria conjuntura sociopolítica do local. No caso da valoração da água, além de sua concepção relacionar-se de antemão com um universo de representações mais próximo da empresa capitalista do que das

\footnotetext{
No mercado das commodities agrícolas, o beldger é o agente econômico que realiza o belding, ou seja, assume uma posição de segurança no mercado de futuros contra flutuações de preços. O objetivo geral da operação é realizar negociações antecipadas através da suposição de situações futuras de mercado.
}

categoriais tradicionalmente fixadas nos territórios rurais, a própria aplicação deste instrumento de gestão deverá refletir as contradições da dialética do território, posto que o gerenciamento regional de águas - através do $\mathrm{CBH}$ e da valoração ambiental, seu principal instrumento de intervenção - acaba sendo realizado em consonância apenas dos interesses dos grupos que possuem acesso à água na região.

Outro indicador da presença marcante dos contextos sociopolíticos territoriais na gestão regional das águas é o conjunto de questões que seguem sendo pauta precípua no CBH-TJ. Neste caso, é sintomática a ausência dos temas relativos às minorias com dificuldades de acesso aos recursos hídricos nas deliberações do comitê. Como exemplo disso, cumpre destacar que no relatório final de diagnósticos regionais para estabelecimento das diretrizes do Plano da Bacia Hidrográfica, apenas as questões técnicas relativas à qualidade dos recursos e à preservação dos mananciais são contempladas (CBH-TJ, 2004b). Ademais, também na definição dos critérios de aplicação dos recursos do Fundo Estadual de Recursos Hídricos na bacia ${ }^{10}$, realizada pelo próprio comitê, as prioridades de investimento foram assim definidas: a) recursos naturais (coleta e tratamento de esgoto, recuperação de voçorocas, conservação do solo, monitoramento da qualidade/quantidade de água, etc); b) educação ambiental e coleta seletiva de lixo; c) gestão integrada de resíduos sólidos; d) drenagem urbana e controle de inundações; e e) outros (CBH-TJ, 2004a).

Se tomarmos por referência a discussão de Santos (2002) acerca do poder como processo distributivo, exercido por constelações de relações que se reforçam ou se neutralizam e que funcionam abrindo novos caminhos ou fixando fronteiras, é possível afirmar que, neste estudo de caso, o modo fixaçãode-fronteiras de exercício do domínio local desempenha função de destaque na manutenção do status quo da governança dos recursos hídricos regionais. Em síntese, podemos apontar ao menos dois processos essenciais envolvidos nesta fixação. O primeiro deles refere-se à manutenção da situação social (e não natural) de ausência de água no cotidiano dos pequenos produtores rurais do município. Ainda que fixados em locais de acesso relativamente fácil à água, estes agricultores seguem socialmente distanciados do recurso. Tal distanciamento tem provocado

10 O Fundo Estadual de Recursos Hídricos (FEHIDRO) fornece o suporte financeiro para a operacionalização da Política Estadual de Recursos Hídricos no Estado de São Paulo. O Fundo é supervisionado por um Conselho de Orientação - o COFEHIDRO -, que é composto paritariamente por representantes do Estado, Municípios e Sociedade Civil. 
inclusive, como já indicado anteriormente, o arrendamento de novas áreas de lavoura para a Unidade Agroindustrial local.

O segundo processo de fixação-de-fronteiras está diretamente relacionado com a frágil situação destes agricultores dentro da estrutura regional de gestão de águas. Sem embargo, a falta de representação no comitê de bacia regional e o desconhecimento do modus operandi desta nova institucionalidade prejudica sobremaneira a inclusão não só das demandas deste segmento na pauta política do comitê de bacia, mas também contribuí para a ausência de diversidades socioculturais nas propostas de construção de alternativas sustentáveis para o uso social da água nos limites da localidade. Com efeito, sem tal diversidade, dificilmente o processo de abertura-de-novos-caminhos adquirirá espaço para novas conjunturas distributivas de poder no contexto sociopolítico não somente da região de estudo, mas também de outros territórios rurais do estado.

\section{CONSIDERAÇÕES FINAIS}

O objetivo deste artigo foi apresentar uma discussão sociológica sobre os limites territoriais da gestão descentralizada dos recursos naturais. Através de um estudo de caso, abordou-se o tema da gestão de águas nas áreas rurais do estado de São Paulo, pontuando alguns dos processos sociais envolvidos na construção de instancias locais de governança territorial.

Conforme discutido ao longo do texto, a problematização da dinâmica sociopolítica dos territórios é de fundamental importância para a avaliação dos limites das novas institucionalidades de gestão socioambiental. O caso de Barra Bonita nos evidenciou que, de fato, as conjunturas locais de exclusão social tendem a serem refletidas nas instâncias descentralizadas de gestão dos recursos territoriais. As estruturas decisórias descentralizadas de gestão de águas - notadamente os Comitês de Bacias Hidrográficas -, embora tecnicamente elaborados e socialmente apresentados como avanços de grande monta na regulação do uso da água e na democratização de seu aparato gestor, podem seguir reproduzindo o conteúdo das relações de poder fixadas no plano da própria localidade.

A conjuntura sociopolítica aqui analisada sugere, em termos de abordagem sociológica, que o estudo das novas instâncias de governança também requer, além da compreensão de suas dimensões institucionais (incluindo a imposição do discurso técnico das burocracias de gestão ambiental, que comumente desloca o saber tradicional para o campo da especulação, identificando-o como nãosaber), também a interpretação dos modos de dominação simbólica e material construídos em conjunturas localizadas. Possivelmente o emprego de esforços desta ordem possibilitará que aspectos como os que envolvem as iniqüidades regionais no acesso à água, por exemplo, venham à tona como processos herdados e, no movimento dialético do território, eventualmente reproduzidos a partir de novas bases sociais.

\section{REFERÊNCIAS}

CASA DA AGRICULTURA ANTÔNIO ORTIGOSSA. Convênio SAA/ Prefeitura - Município de Barra Bonita. Barra Bonita: Escritório de Desenvolvimento Rural de Jaú, 2001. 63p.

CBH-TJ-Comitê da Bacia Hidrográfica do Tietê-Jacaré. Ata da $2^{a}$ Reunião Plenária CBH-TJ, realizada no dia 27 de maio de 2004. Disponível em: <www.sigrh.sp.gov. br>. 2004a.

CBH-TJ-Comitê da Bacia Hidrográfica do Tietê-Jacaré. Diagnóstico da Situação Atual dos Recursos Hídricos e Estabelecimento e Diretrizes Técnicas para a Elaboração do Plano da Bacia Hidrográfica do Tietê-Jacaré. CBH-TJ/FEHIDRO. Disponível em: www.sigrh.sp.gov.br. 2004b.

FURTADO, L.G. Pescadores do Rio Amazonas: um estudo antropológico da pesca ribeirinha numa área amazônica. Belém: Museu Paraense Emílio Goeldi, 1993. 486p.

GODELIER, M. Economia e Sociedade. In: CARVALHO, E. de A. (Org.) Godelier - Antropologia. São Paulo: Ática, 1981, p.47-58. (Coleção Grandes Cientistas Sociais).

LEFF, E. A Geopolítica da Biodiversidade e o Desenvolvimento Sustentável: economização do mundo, racionalidade ambiental e reapropriação social da natureza. In: MARTINS, R. C.; VALENCIO, N. F. (Orgs.). Uso e Gestão dos Recursos Hídricos no Brasil. v. 2: desafios teóricos e político-institucionais. São Carlos: RiMa, 2003. p.1-19. 
MARTINS, R.C. A Construção Social do Valor Econômico da Água: estudo sociológico sobre agricultura, ruralidade e valoração ambiental no estado de 20. 2004. 258f. Tese (Doutorado) - Universidade de São Paulo, PPG-SEA, São Paulo, $2004 a$.

; VALENCIO, N.F.L.S. Valoração dos Recursos Hídricos e Impasse Sócio-Ambiental na Agricultura Paulista: alguns desafios para a gestão de políticas públicas. Informações Econômicas, v.33, n.10, p. 28-40, out. 2003.

PATTON, M.Q. Qualitative Research and Evaluation Methods. $3^{\mathrm{a}} \mathrm{ed}$. London: Sage Publications, 2002, 179p.

ROUSSEAU, J.J. Discurso Sobre a Origem e o Fundamento da Desigualdade Entre os Homens. Os Pensadores. 5 ed. São Paulo: Nova Cultural, 1991. p. 201-320.

SANTOS, B.S. A Crítica da Razão Indolente: contra o desperdício da experiência. São Paulo: Cortez, 2002. 415p.

SÃO PAULO. Relatório de situação dos recursos hídricos do estado de São Paulo. São Paulo: Conselho Estadual de Recursos Hídricos-CRH/Comitê Coordenador do Plano Estadual de Recursos Hídricos-CORHI, 2000, 128p.

SCHENEIDER, F; VOLKERT, J. No chance for incentive-oriented environmental policies in representative democracies? A Public Choice analysis. Ecological Economics, n.31, p.123-138, 1999.

THOMPSON, E.P. A Miséria da Teoria ou um Planetário de Erros: uma crítica ao pensamento de Althusser. Rio de Janeiro: Zahar, 1981.

Texto submetido à Revista em 22.9.2010

Aceito para publicação em 19.12.2010 